\title{
SISTEM PENDUKUNG KEPUTUSAN PENERIMAAN BLT DI KECAMATAN SAMPANG MENGGUNAKAN METODE SAW DAN METODE AHP BERBASIS WEB
}

\author{
Rehadian Teja Sukmana Putra, Suryo Adi Wibowo, Yosep Agus Pranoto \\ Program Studi Teknik Informatika S1, Fakultas Teknologi Industri \\ Institut Teknologi Nasional Malang, Jalan Raya Karanglo km 2 Malang, Indonesia \\ reihanjr27@gmail.com
}

\begin{abstract}
ABSTRAK
Program bantuan langsung tunai untuk keluarga miskin atau yang biasa dikenal dengan istilah BLT merupakan salah satu upaya pemerintah untuk mengurangi beban pengeluaran keluarga miskin. Namun pada praktek lapanganya, pengambilan keputusan untuk menentukan kriteria penerima bantuan langsung tunai yang sudah terjadi biasanya tidak mengacu pada kriteria-kriteria keluarga miskin, diperlukan sebuah sistem informasi untuk mengurangi tingkat kesalahan dan kecurangan. Pembuatan Sistem Pendukung Keputusan (SPK) ini bertujuan sebagai alat bantu bagi instalasi yang terkait, untuk menentukan penerima bantuan langsung tunai secara tepat sasaran dalam penyaluran bantuan langsung tunai tersebut. Agar tujuan dari sistem ini dapat tercapai maka harus didukung dengan menggunakan salah satu metode dalam pengambilan keputusan yaitu metode Simple Additive Weighting (SAW) dan Analytic Hierarchy Proces (AHP) untuk mengevaluasi alternatif penerimaan bantuan langsung tunai berdasarkan kriteria-kriteria pengambilan keputusan. Berdasarkan hasil pengujian fungsional sistem, menunjnukkan bahwa proses input data dan fungsi utama pada sistem dapat berjalan dengan tingkat keberhasilan $100 \%$. Dan penerapan metode SAW dan AHP pada sistem pendukung keputusan ini menghasilkan nilai rata-rata eror sebesar $0 \%$ yang didasarkan pada tabel pengujian sistem.
\end{abstract}

Kata Kunci : Sistem Pendukung Keputusan, Simple Additive Weighting, Analythic Hierarchy Process

\section{PENDAHULUAN}

\subsection{Latar Belakang}

Program bantuan langsung tunai untuk keluarga miskin atau yang biasa dikenal dengan istilah BLT merupakan salah satu upaya pemerintah untuk mengurangi beban pengeluaran keluarga miskin. Melalui program bantuan langsung tunai diharapkan berdampak langsung terhadap peningkatan kesejahteraan dan ketahanan ekonomi keluarga miskin. Namun pada praktek lapanganya, pengambilan keputusan untuk menentukan kriteria penerima bantuan langsung tunai yang sudah terjadi biasanya tidak mengacu pada kriteria-kriteria keluarga miskin, diperlukan sebuah sistem informasi yang baik untuk mengurangi tingkat kesalahan dan kecurangan yang dilakukan oleh pihak-pihak tertentu. Sistem pendukung keputusan (SPK) merupakan bagian dari sistem informasi berbasis komputer yang dapat mengatasi masalah ini, sistem ini berguna untuk memudahkan pengambilan keputusan yang terkait dengan masalah seleksi penerima bantuan langsung tunai untuk keluarga miskin, sehingga akan didapatkan keluarga yang paling layak diberi bantuan langsung tunai.

Pembuatan Sistem Pendukung Keputusan (SPK) ini bertujuan sebagai alat bantu bagi instalasi yang terkait, untuk menentukan penerima bantuan langsung tunai secara tepat sasaran dalam penyaluran bantuan langsung tunai tersebut. Agar tujuan dari sistem ini dapat tercapai maka harus didukung dengan menggunakan salah satu metode dalam pengambilan keputusan yaitu metode Simple Additive
Weighting (SAW) dan Analytic Hierarchy Proces (AHP) untuk mengevaluasi alternatif penerimaan bantuan langsung tunai berdasarkan kriteria-kriteria pengambilan keputusan.

\subsection{Rumusan Masalah}

Berdasarkan latar belakang tersebut, maka masalah yang ada dan harus diselesaikan adalah sebagai berikut :

1. Bagaimanakah membangun aplikasi sistem pendukung keputusan dengan penerapan metode Simple Additive Weighting (SAW) dan Analytic Hierarchy Proces (AHP) untuk memberikan pilihan yang lebih akurat?

2. Bagaimana menentukan penerima bantuan langsung tunai dengan kriteria terbaik berdasarkan urutan prioritas?

\subsection{Batasan Masalah}

Batasan masalah dari pembuatan proposal ini adalah :

1. Sistem Pendukung Keputusan untuk memilih warga yang berhak menerima bantuan langsung tunai menggunakan metode Simple Additive Weighting (SAW) dan Analytic Hierarchy Proces (AHP).

2. Kriteria-kriteria penerima bantuan langsung tunai adalah sebagai berikut :

(1) Pekerjaan

(2) Penghasilan Per - Bulan

(3) Tanggungan Keluarga

(4) Kepemilikan Aset 


\section{(5) Tempat Tinggal}

\section{TINJAUAN PUSTAKA}

\subsection{Penelitian Terdahulu}

Al Fath Riza Kholdani (2017),melakukan penelitian tentang Sistem Pendukung Keputusan Penilaian Kinerja Dosen dengan Metode AHP dan SAW". Pada kesimpulan jurnal ini adalah membuat Rancangan sistem pendukung keputusan dengan menerapkan metode analytic hierarchy process(AHP) dan metode simple additive weighting(SAW) untuk menentukan penilaian kinerja dosen menilai aspek kompetensi. Dimana aspek kompetensi yang dinilai adalah kompetensi profesional, kompetensi sosial, kompetensi kepribadian dan kompetensi agama. [1]

Andrea graselita (2017), melakukan penelitian tentang Sistem Pendukung Keputusan Pemilihan Karyawan Terbaik dengan Metode Simple Additive Weighting (SAW)". Metode Simple Additive Weighting (SAW) digunakan untuk mendukung pengambilan keputusan dalam proses pemilihan karyawan terbaik terutama dalam proses perangkingan berdasarkan kriteria kriteria telah ditentukan sehingga dapat memberikan rekomendasi pemilihan karyawan terbaik yang lebih objektif karena dapat dilakukan pembobotan terhadap kriteria yang telah ditentukan.[2]

Angga pramudhita (2017), melakukan penelitian tentang Sistem Pendukung Keputusan Pemilihan Rumah Kost Putra Di Kota Malang Dengan metode Simple Additive Weighting (SAW)". Dalam metode ini menentukan nilai bobot untuk setiap atribut, kemudian dilanjutkan dengan proses perankingan yang akan menyeleksi alternatif terbaik dari sejumlah alternatif, dalam hal ini alternatif yang dimaksud adalah rumah kost yang memiliki kriteria sesuai dengan yang diinginkan calon penghuni kost. Dengan metode perangkingan tersebut, diharapkan penilaian akan lebih tepat karena didasarkan pada nilai kriteria dan bobot yang sudah ditentukan sehingga akan mendapatkan hasil yang lebih akurat dan optimal terhadap rumah kost yang akan dipertimbangkan oleh pengambil keputusan.[3]

Faizal suwarto (2017), melakukan penelitian tentang Sistem Pendukung Keputusan Seleksi Administrasi Peserta Didik Baru TK Cendekia Agung Dengan metode Simple Additive Weighting (SAW)". Dalam metode ini sangat cocok digunakan dalam seleksi administrasi penerimaan peserta didik baru karena metode ini akan digunakan untuk menghitung nilai bobot setiap atribut, kemudian dilakukan proses pengurutan.[4]

Suyono abubakar (2018), melakukan penelitian tentang Sistem Pendukung Keputusan Pemilihan Objek Wisata Kota Labuan Bajo Dengan metode Simple Additive Weighting (SAW)". Dalam metode ini menentukan nilai bobot untuk setiap atribut, kemudian dilanjutkan dengan proses perankingan yang akan menyeleksi alternatif terbaik dari sejumlah alternatif.. Dengan metode perangkingan tersebut, diharapkan penilaian akan lebih tepat karena didasarkan pada nilai kriteria dan bobot yang sudah ditentukan sehingga akan mendapatkan hasil yang lebih akurat dan optimal terhadap pemilihan objek wisata tersebut yang akan dipertimbangkan oleh pengambil keputusan.[5]

\subsection{Sistem Pendukung Keputusan}

Definisi sistem pendukung keputusan adalah sistem informasi yang berbasis komputer serta berbasis pengetahuan yang dapat digunakan dalam pengambilan keputusan di dalam instalasi atau perusahaan.

\subsection{Metode Simple Additive Weighting}

Metode Simple Additive Weighting (SAW) sering juga dikenal istilah metode penjumlahan terbobot. Konsep dasar metode SAW adalah mencari penjumlahan terbobot dari rating kinerja pada setiap alternatif pada semua kriteria. Andrea graselita (2017) telah melakukan penelitian tentang “ Sistem Pendukung Keputusan Pemilihan Karyawan Terbaik Menggunakan Metode SAW untuk mengambil keputusan dalam proses pemilihan karyawan terbaik".

\subsection{Metode Analythic Hierarchy Process}

Metode AHP adalah sebuah kerangka untuk mengambil keputusan dengan efektif atas persoalan yang kompleks dengan menyederhanakan dan mempercepat proses pengambilan keputusan dengan memecahkan persoalan tersebut kedalam bagianbagiannya, menata bagian atau variabel ini dalam suatu susunan hirarki,memberi nilai numerik pada pertimbangan subjektif tentang pentingnya tiap variabel dan mensintesis berbagai pertimbangan ini untuk menetapkan variabel yang mana memiliki prioritas paling tinggi dan bertindak untuk mempengaruhi hasil pada situasi tersebut. Al Fath Kholdani (2017) telah melakukan penelitian tentang “ Sistem Pendukung Keputusan Penilaian Kinerja Dosen menggunakan metode AHP dan SAW".

\subsection{PHP (Hypertext PreProcessor)}

PHP adalah bahasa pemrograman script serverside yang didesain untuk pengembangan web. Selain itu, PHP juga bisa digunakan sebagai bahasa pemrograman umum. PHP di kembangkan pada tahun 1995 oleh Rasmus Lerdorf, dan sekarang dikelola oleh The PHP Group. Menurut website Qwords (2020) "PHP adalah bahasa pemograman server-side yang digunakan dalam pembuatan website bersama dengan CSS dan HTML. PHP merubah website dari statis menjadi lebih dinamis serta fungsi website yang lebih interaktif untuk keperluan user".

\subsection{Mysql (My Structured Query Languange)}

MySQL kependekan dari (My Structured Query Language) merupakan program pembuat dan pengelola database atau sering disebut dengan $D B M S$ 
yang mana singkatannya (Database Management System), DBMS ini bersifat open source, artinya kita dapat mendapatkannya secara gratis suatu database yang bersifat jaringan, sehingga dapat digunakan untuk aplikasi Multi User atau banyak pengguna.

\section{METODE PENELITIAN}

\subsection{Analisa Kebutuhan}

Program bantuan langsung tunai untuk keluarga miskin atau yang biasa dikenal dengan istilah BLT merupakan salah satu upaya pemerintah untuk mengurangi beban pengeluaran keluarga miskin. Melalui program tersebut, diharapkan berdampak langsung terhadap peningkatan kesejahteraan dan ketahanan ekonomi keluarga miskin.

Namun pada praktek lapangannya, pengambilan keputusan untuk menentukan kriteria penerima bantuan langsung tunai yang sudah terjadi biasanya tidak mengacu pada kriteria - kriteria keluarga miskin. Untuk itu diperlukan sebuah sistem pendukung keputusan yang baik untuk mengurangi tingkat kesalahan dan kecurangan yang dilakukan oleh pihak - pihak tertentu. Sehingga akan didapatkan keluarga yang paling layak diberi bantuan langsung tunai.

\subsection{Kebutuhan Fungsional}

Dibawah ini adalah penjelasan tentang kebutuhan fungsional, kebutuhan yang perlu ada untuk admin agar aplikasi dapat berjalan dengan baik sesuai dengan yang dibutuhkan :

1. Dapat menginputkan dan merubah data warga.

2. Menginputkan nilai kriteria warga.

3. Menampilkan hasil rangking dari warga yang terpilih.

\subsection{Perancangan Sistem}

Dalam pengembangan teknologi informasi saat ini, dibutuhkan sistem untuk menentukan penerimaan bantuan langsung tunai di instalasi terkait. Sistem pendukung keputusan tersebut di harapkan untuk bisa memutuskan dan memilih yang berhak menerima bantuan langsung tunai secara cepat dan tepat. Analisis merupakan cara untuk menyelesaikan permasalahan berdasarkan data yang telah diperoleh dari hasil studi lapangan. Sedangkan desain sistem ini ada beberapa tahapan - tahapan yang harus dilakukan. Adapun tahapan - tahapan dalam perancangan sistem yang dilakukan adalah usecase diagram dan flowchart.

\subsection{Diagram Alur Metodologi Penelitian}

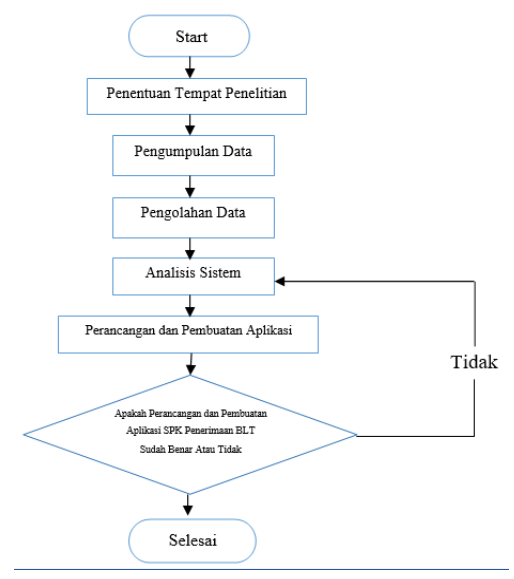

Gambar 1 Diagram Alur Metodologi Penelitian

\subsection{Flowchart Metode}

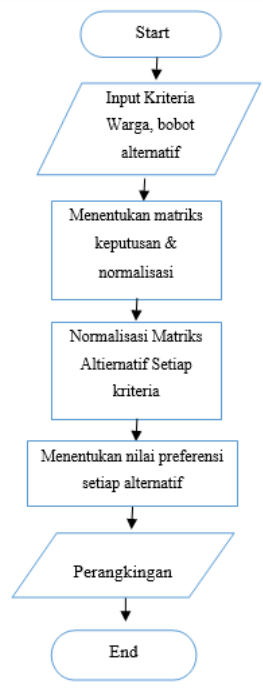

Gambar 2. Flowchart Metode

\subsection{Flowchart User Admin}

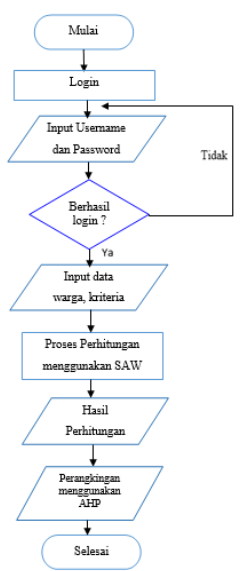

Gambar 3. Flowchart User Admin 


\subsection{Flowchart User Warga}

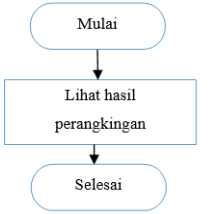

Gambar 4. Flowchart User Warga

\subsection{Use Case Diagram}

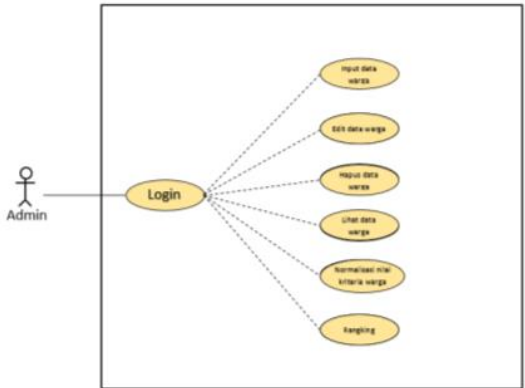

Gambar 5. Use Case Diagram

\section{9. $\mathrm{CDM} \& \mathrm{PDM}$}

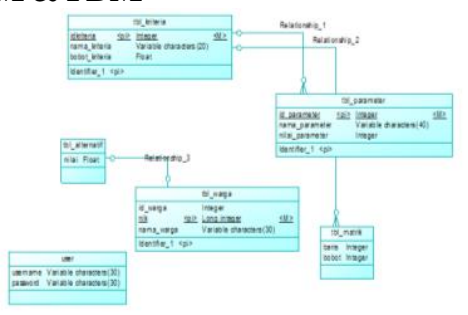

Gambar 6. CDM

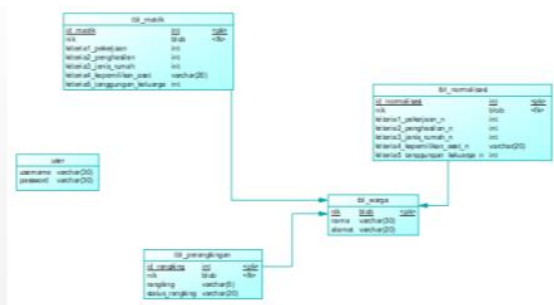

Gambar 7. PDM

3.10. ERD

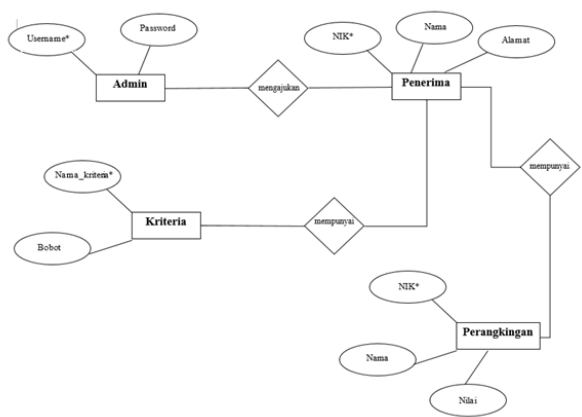

Gambar 8. ERD

\subsection{Struktur Menu}

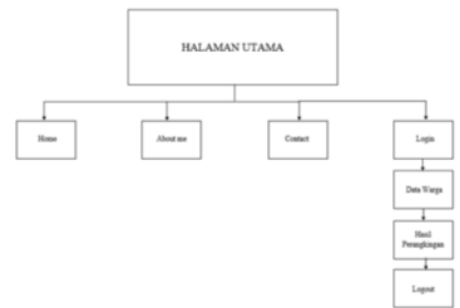

Gambar 9. Struktur Menu

\section{HASIL DAN PEMBAHASAN}

\subsection{Halaman Login}

Pada gambar 10 merupakan halaman login. Admin / user memasukkan username dan password kemudian tekan tombol login.

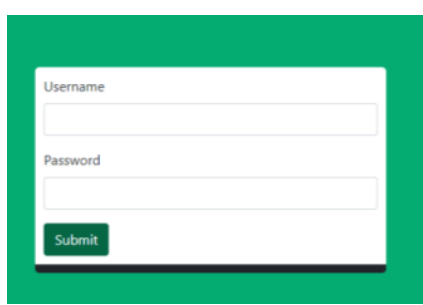

Gambar10. Halaman Login

\subsection{Halaman Menu Utama}

Pada gambar 11 merupakan halaman menu utama. Halaman menu utama adalah form yang berisi tentang penjelasan BLT dan 10 teratas yang menerima BLT.

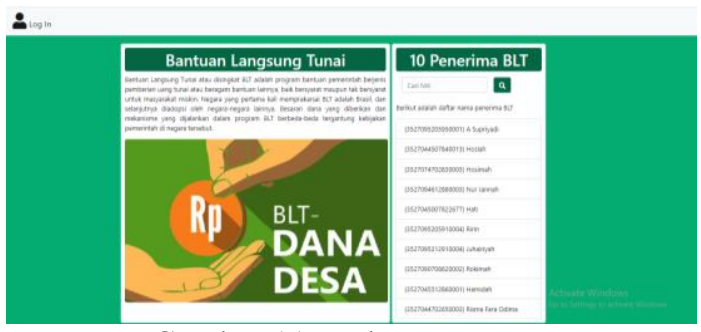

Gambar 11. Halaman Utama

\subsection{Halaman Input Data Warga}

Pada gambar 12 merupakan halaman input data warga. halaman input data warga adalah form yang digunakan untuk menginputkan setiap data warga.

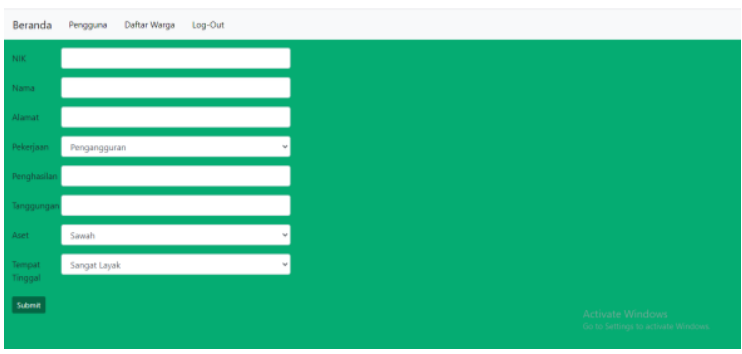

Gambar 12. Halaman Input Data Warga 


\subsection{Halaman Data Warga}

Pada gambar 13 merupakan halaman daftar data warga . Halaman daftar periode adalah form yang digunakan untuk melihat daftar data periode.

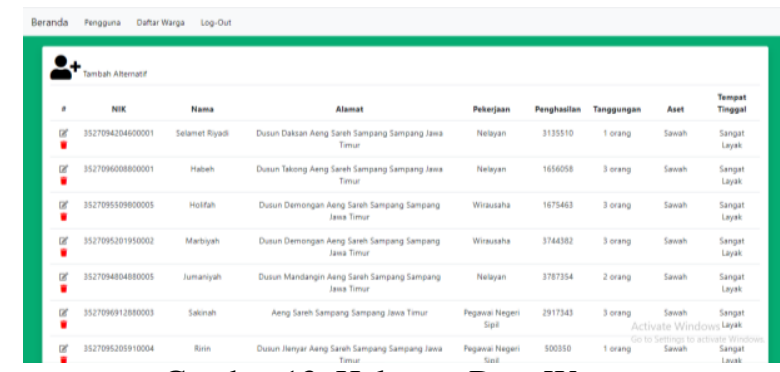

Gambar 13. Halaman Data Warga

4.5. Halaman Perhitungan dan Rangking

Pada gambar 14 merupakan halaman perhitungan bobot dari kriteria warga

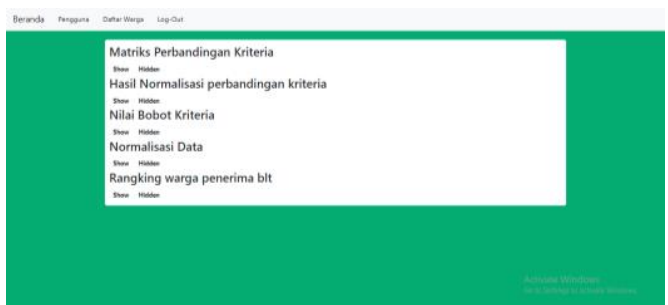

Gambar 14. Halaman Perhitungan dan Perangkingan

\subsection{Halaman Matriks Perbandingan Kriteria}

Pada gambar 15 merupakan halaman penentuan matriks perbandingan kriteria

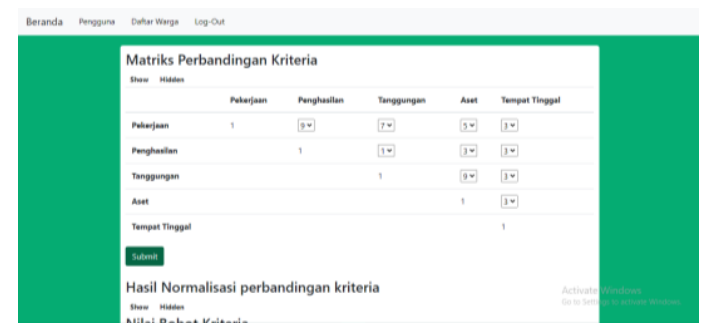

Gambar 15. Halaman Matriks Perbandingan Kriteria

\subsection{Halaman Normalisasi Perbandingan Kriteria}

Pada gambar 16 ini merupakan halaman normalisasi perbandingan kriteria

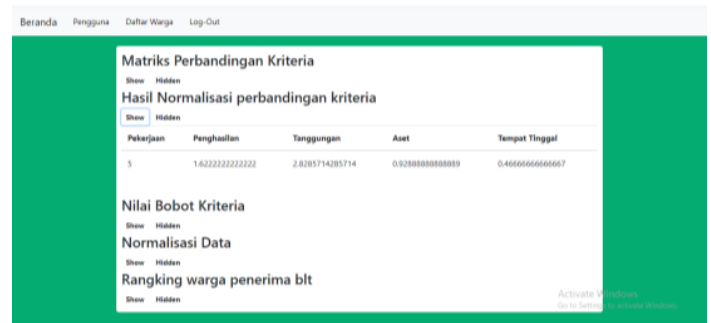

Gambar 16. Halaman Normalisasi Perbandingan Kriteria

\subsection{Halaman Bobot Kriteria}

Pada gambar 17 ini merupakan halaman pembobotan dari setiap kriteria

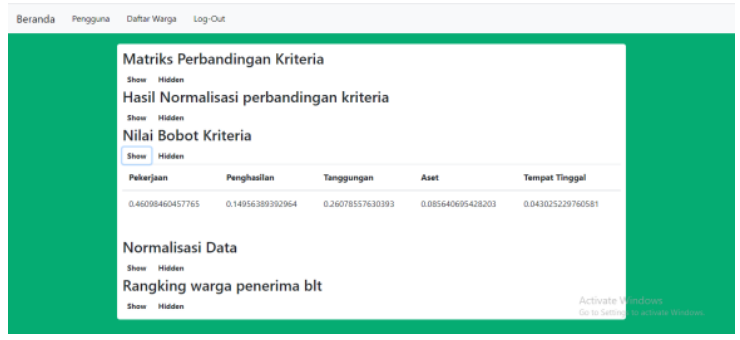

Gambar 17. Halaman Bobot Kriteria

\subsection{Halaman Normalisasi Data}

Pada gambar 18 merupakan halaman normalisasi data dari setiap data

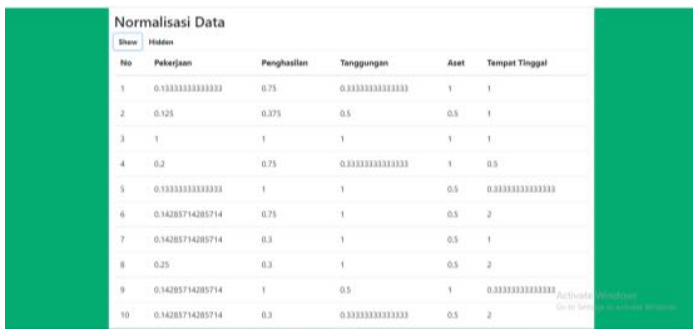

Gambar 18. Halaman Normalisasi Data

\subsection{Halaman Rangking Penerima BLT}

Pada gambar 19 ini merupakan halaman perangkingan setelah proses perhitungan

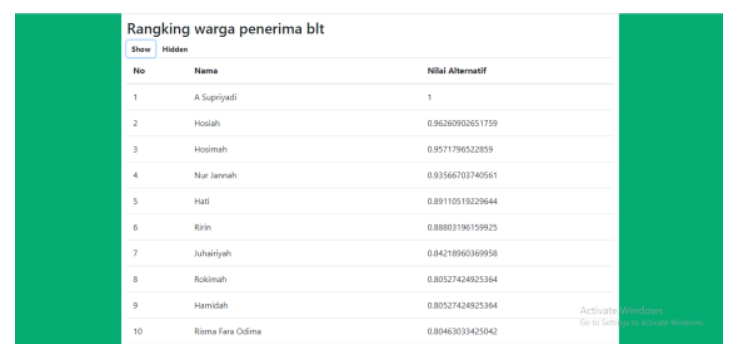

Gambar 19. Halaman Rangking Warga Penerima BLT

\subsection{Pengujian fungsional sistem}

Pengujian fungsional sistem dilakukan untuk menguji apakah fitur-fitur yang ada pada sistem pendukung keputusan penerimaan BLT ini berjalan dengan baik atau tidak. Hasil pengujian fungsional sistem ditunjukan pada Tabel1.

Tabel 1. Hasil Pengujian Fungsional Sistem

\begin{tabular}{|c|l|c|c|}
\hline \multirow{2}{*}{ No } & \multirow{2}{*}{ Fungsi yang diuji } & \multicolumn{2}{|c|}{ Browser } \\
\cline { 3 - 4 } & $\begin{array}{c}\text { Google } \\
\text { Chrome }\end{array}$ & $\begin{array}{c}\text { Uc } \\
\text { Browser }\end{array}$ \\
\hline 1 & Tampil halaman login & $\checkmark$ & $\checkmark$ \\
\hline 2 & $\begin{array}{l}\text { Tampil halaman } \\
\text { utama }\end{array}$ & $\checkmark$ & $\checkmark$ \\
\hline 3 & Tampil data kriteria & $\checkmark$ & $\checkmark$ \\
\hline 4 & Input data warga & $\checkmark$ & $\checkmark$ \\
\hline 5 & Ubah data warga & $\checkmark$ & $\checkmark$ \\
\hline
\end{tabular}




\begin{tabular}{|c|l|c|c|}
\hline 6 & Hapus data warga & $\checkmark$ & $\checkmark$ \\
\hline 7 & $\begin{array}{l}\text { Penentuan matriks } \\
\text { perbandingan kriteria }\end{array}$ & $\checkmark$ & $\checkmark$ \\
\hline 8 & $\begin{array}{l}\text { Tampil normalisasi } \\
\text { perbandingan kriteria }\end{array}$ & $\checkmark$ & $\checkmark$ \\
\hline 9 & $\begin{array}{l}\text { Tampil nilai bobot } \\
\text { kriteria }\end{array}$ & $\checkmark$ & $\checkmark$ \\
\hline 10 & $\begin{array}{l}\text { Tampil normalisasi } \\
\text { data }\end{array}$ & $\checkmark$ & $\checkmark$ \\
\hline 11 & $\begin{array}{l}\text { Tampil hasil } \\
\text { perangkingan }\end{array}$ & $\checkmark$ & $\checkmark$ \\
\hline 12 & Logout & $\checkmark$ & $\checkmark$ \\
\hline
\end{tabular}

\subsection{Pengujian Perhitungan Metode}

Pengujian sistem perhitungan ini dilakukan dengan membandingkan hasil akhir perhitungan manual dengan perhitungan sistem dimana hasil perbandingan tersebut akan mengetahui berapa besar prosentasi erorrnya seperti yang ditunjukkan pada Tabel 2. berikut.

Tabel 2. Tabel Hasil Perhitungan Manual dengan Perhitungan Sistem

\begin{tabular}{|c|c|c|c|c|}
\hline Alternatif & $\begin{array}{c}\text { Hasil } \\
\text { Perhitungan } \\
\text { Sistem }\end{array}$ & $\begin{array}{c}\text { Hasil } \\
\text { Perhitungan } \\
\text { Manual }\end{array}$ & Selisih & $\begin{array}{c}\text { Eror } \\
\text { sistem }\end{array}$ \\
\hline $\begin{array}{c}\text { Buadah } \\
\text { Al Hasib }\end{array}$ & 0,384 & 0,384 & 0 & $0 \%$ \\
\hline Rohmah & 0,411 & 0,411 & 0 & $0 \%$ \\
\hline Butiyah & 0,414 & 0,414 & 0 & $0 \%$ \\
\hline Dawatul & 0,414 & 0,414 & 0 & $0 \%$ \\
\hline Beah & 0,420 & 0,420 & 0 & $0 \%$ \\
\hline \multicolumn{5}{|l}{ Jumlah rata-rata eror } \\
\end{tabular}

\section{KESIMPULAN DAN SARAN}

\subsection{Kesimpulan}

Setelah melalui tahap analisa dan pengujian pada sistem pendukung keputusan penerimaan bantuan langsung tunai menggunakan metode simple additive weighting (SAW) dan analythic hierarchy process (AHP), maka dapat diambil beberapa kesimpulan sebagai berikut :

1. Sistem pendukung keputusan penerimaan bantuan langsung tunai dengan menggunakan metode Simple Additive Weighting (SAW) dan analythic hierarchy process (AHP) digunakan untuk mendukung pengambilan keputusan penerimaan bantuan langsung tunai terutama dalam proses perangkingan berdasarkan kriteria - kriteria telah ditentukan sehingga dapat memberikan rekomendasi evaluasi pemilihan penerimaan bantuan langsung tunai yang lebih objektif karena dapat dilakukan pembobotan terhadap kriteria yang telah di tentukan.

2. Berdasarkan hasil pengujian fungsional sistem, menunjnukkan bahwa proses inout data dan fungsi utama pada sistem dapat berjalan dengan tingkat keberhasilan $100 \%$.

3. Penerapan metode SAW dan AHP pada sistem pendukung keputusan ini menghasilkan nilai rata-rata eror sebesar $0 \%$ yang didasarkan pada tabel pengujian sistem dengan data uji sampel sebanyak 5(lima) yang dihitung secara manual dan dibandingkan dengan perhitungan yang dilakukan oleh sistem.

4. Pengujian sistem ini dari sisi fungsional dapat membantu instansi terkait dalam menentukan penerima bantuan langsung tunai secara tepat sasaran.

\subsection{Saran}

Berdasarkan penelitian yang telah dilakukan, maka penulis dapat memberikan saran-saran untuk pengembangan selanjutnya antar lain :

1. Tampilan halaman perhitungan didesain dengan lebih mudah agar user friendly.

2. Mengembangkan sistem menjadi sisitem informasi penerimaan BLT melalui website.

3. Menambahkan fitur periode pada penerimaan BLT.

\section{DAFTAR PUSTAKA}

[1] Endang Lestari."Kolaborasi Metode SAW dan AHP Untuk Sistem Pendukung Keputusan Penilaian Kinerja Asisten Laboratorium". https://ejournal.unsri.ac.id/index.php/jsi/article/v iew/4204 . (1 April 2017).

[2] Al Fath Riza Kholdani ${ }^{1}$, Muflih $^{2}$, Nur Arminarahma ${ }^{3}$."Sistem Pendukung Keputusan Penilaian Kinerja Dosen Dengan Metode AHP dan SAW". https://jtiulm.ti.ft.ulm.ac.id/index.php/jtiulm/arti cle/download/14/13.(1 Juni 2017).

[3] Andrea Graselita Beatrix Saquera."Sistem Pendukung Keputusan Pemilihan Karyawan Terbaik Dengan Metode SAW (Studi Kasus PT.FOCUS DISTRIBUTION NUSANTARA SURABAYA) Berbasis Desktop". https://ejournal.itn.ac.id/index.php/jati/article/vi ew/1959 . (1 Maret 2017).

[4] Dwi Aris Rahmadani."Sistem Pendukung Keputusan Pemilihan Lingkungan Sekolah Terbaik di Kota Pasuruan Menggunakan Metode WP( Weighted Product) Berbasis Website". https://ejournal.itn.ac.id/index.php/jati/article/vi ew/1888 . (1 Maret 2017).

[5] Faizal Suwarto."Sistem Pendukung Keputusan Seleksi Administrasi Peserta Didik Baru TK Cendekia Agung Dengan Metode SAW". https://ejournal.itn.ac.id/index.php/jati/article/vi ew/465. (2 September 2017)

[6] Suyono Abubakar."Pengembangan Sistem Pendukung Keputusan Pemilihan Objek Wisata Kota Labuhan Bajo Menggunakan Metode Simple Additive Weighting(SAW)". https://ejournal.itn.ac.id/index.php/jati/article/vi ew/469 . (2 September 2018).

[7] Taufiq, Rohmat. 2020. Sistem Pendukung Keputusan Pengantar,Contoh Soal dan Pembahasan Menggunakan Metode Grafik,Simpleks,SAW,TOPSIS,AHP. Bogor: Penerbit Mitra Wacana Media. 
[8] Setiyaningsih, Wiji. 2015. Konsep Sistem Pendukung Keputusan. Malang: Yayasan Edelweis .

[9] Marisa, Fitri. 2017. Web Prigramming Clien Side andt Server Side Untuk Membangun Poertal. Yogyakarta: Deepublish.

[10] Filipova, Olga, and Rui Vilão. 2018. Software Development From A to Z A Deep Dive into all the Roles Involved in the Creation of Software. Berlin, Germany: Apress.

[11] Rif'an. 2015. Implementasi Metode AHP-WP pada sistem pendukung keputusan pemilihan guru teladan. http://lib.unnes.ac.id/26597/1/4111411025.pdf
[12] Ulum. 2016. Sistem Pendukung Keputusan pemilihan siswa berprestasi menggunakan metode AHP (Analytical Hierarchy Process)

[13] Orlando. 2015. Sistem Pengambil Keputusan penentuan siswa berprestasi pada sekolah menengah atas negeri 1 Maumere menggunakan metode AHP

[14] Dudung. 2016. Pengertian Komponen dan Fungsi XAMPP Lengkap dengan Penjelasannya. Yayasan Edelweis

[15] Putra. 2017. Pengembangan Sistem Pendukung Keputusan pemilihan objek wisata di Malang dengan menggunakan metode SAW. Penerbit Mitra Wacana Media 